\title{
Interaction of Gums and Antimicrobial Agents on Susceptibility of Selected Foodborne Pathogens
}

\section{Karlton-Senaye B ${ }^{\star}$, Ayad A, Davis S, Khatiwada J and Williams L}

Center for Excellence in Post Harvest Technologies, North Carolina Research Campus, North Carolina Agricultural and Technical State University, Kannapolis, North Carolina, United States

"Corresponding author: Bernice Dzifa Karlton-Senaye, Center for Excellence in Post Harvest Technologies, The North Carolina Research Campus, UNC Nutrition Research Building, 500 Laureate Way, Kannapolis, NC 28081, USA, Tel: 704-250-5700; Fax: 704-250-5709; E-mail: bekarlton@gmail.com

Received date: May 09, 2016; Accepted date: June 20, 2016; Published date: June 29, 2016

Copyright: (c) 2016 Karlton-Senaye B, et al. This is an open-access article distributed under the terms of the Creative Commons Attribution License, which permits unrestricted use, distribution, and reproduction in any medium, provided the original author and source are credited.

\begin{abstract}
The objective of this study was to determine the combined effect of locust bean, xanthan, agar, carrageenanmaltodextrin and pectin gums on the growth, bacterial survival, and susceptibility of foodborne pathogens. The combine effect five different gums and antimicrobial agents (Tetracycline, Doripenem, Imipenem, Cefixime, Cipropoxacin, Ceftazidime, Kanamycin and Meropenem) on susceptibility of foodborne pathogens was tested using disc diffusion method. Amongst gums tested, treatment with carrageenan-maltodextrin $(52.00 \pm 2.00 \mathrm{~mm})$ and pectin $(51.00 \pm 1.00 \mathrm{~mm})$ resulted in a two-fold increased in susceptibility of Salmonella enterica to imipenem $10 \mu \mathrm{g}$, compared to the control $(25.33 \pm 1.00 \mathrm{~mm})$. Treatment with locust bean and agar gums also led to a two-fold increase in susceptibility of Salmonella enterica to cefixime and xanthan also increased susceptibility Escherichia coli $0157: \mathrm{H} 7$ to doripenem. Addition of gums led to a slight increase or decrease on bacterial growth in treatment compared to control. Bacterial survival decreased in the presence of all gums during refrigerated storage with pectin producing a $\log 2.68 \pm 0.10 \mathrm{CFUml}^{-1}$ reduction. Tested gums could potentially be used in combination with antimicrobial medicines to improve their efficacy in the treatment of Salmonella enterica, Staphylococcus aureus, Listeria monocytogenes and Escherichia coli O157:H7 infections. Our findings could potentially lead to synergistic use of gums and antimicrobial agents to enhance the treatment and reduce recovery period of foodborne infections leading to less dependence on antimicrobial medicines and subsequently promoting health.
\end{abstract}

Keywords: Gums; Antimicrobial agents; Susceptibility; Salmonella enterica; Escherichia coli O157:H7; Staphylococcus aureus, Listeria monocytogenes

\section{Introduction}

Foodborne pathogens still remain one of the major causes of illness and fatalities in the world. In the United States food safety is still a problem as food contamination by pathogens, which are harmful to humans, has been estimated to lead to about 3000 fatally and 128,000 cases of hospitalization each year [1]. Enterohemorrhagic Escherichia coli O157:H7, Listeria monocytogenes and Salmonella enterica are the top three pathogens responsible for foodborne illnesses and deaths $[2,3]$.

In addition to causing food safety issues, pathogens also target farm animals causing diseases and deaths. In some cases livestock such as cattle serve as major reservoirs for pathogens specifically Escherichia coli $\mathrm{O} 157: \mathrm{H} 7$ resulting in contaminated meat, fruit and vegetables for human consumption [3]. Antimicrobial agents are used in animals to treat diseases, to safeguard the health and safety of farm animals, and to promote growth and feed efficiency [4]. Continuous and indiscriminate uses of such antimicrobial agents often cause passage of antimicrobial medicines to humans through the food chain resulting in issues of antibiotic resistance.

Infections from foodborne pathogens are often treated with prescribed antimicrobial agents. Whereas some bacteria may be inherently resistant to different types of antimicrobial agents long-term exposure of such antimicrobial medicines to both humans and animals has resulted in increasing antimicrobial resistance in humans who depend on live stocks as sources of food [5]. Frequent use of antimicrobial agents for the treatment of infection generally result in declining levels of microflora in human gastrointestinal tract, causing the growth of pathogenic bacteria to reach high numbers [3].

Lactic acid, specifically, Lactobacillus, also known as probiotic are normal residents of the human gastrointestinal tract have been used for fermentation in the food industry with a high recognition for their beneficial therapeutic health effects [6-8]. To reduce the overdependence on antimicrobial agents, certain polysaccharides have gained attention as therapeutic products that can replace [9] or combine with antimicrobial agents to improve improve gut health. Yamashita et al. [9] have studied the bacteriostatic effects of dietary polysaccharides on the growth of eight different pathogenic bacteria including Salmonella enterica, Staphylococcus aureus, Listeria monocytogenes and Escherichia coli O157:H7 and have found that pectin and carrageenan have antimicrobial properties. Recent studies by Daoud et al. [10] have also shown that pectin exerted antibacterial effect against Helicobacter pylori that causes gastritis and peptic ulcers [10].

Polysaccharides, specifically gums are hydrophilic agents obtained from plants (both land and seaweeds), animals, and microbial fermentation that comprise many hydroxyl groups, high molecular weight, and highly branched structure [11,12]. Gums are used either singly or in combination with proteins, lipids or other gums in various food products to enhance viscosity, mouth feel, texture and as a preservative [13]. Gums have also been used in other industries, namely pharmaceutical, cosmetic, paint, inks, paper, color, and 
adhesive industries [14]. Gums have also served as growth and viability enhancers of certain probiotic Lactobacillus strains [12,15-18].

Although many studies reported the impact of gums on the growth of probiotics $[12,17,18]$ the combined effect of these gums on the growth, fatality and antibiotic susceptibility of pathogens, have not been studied. Therefore the aim of this study is to investigate the effect of gums on the growth of pathogenic microorganisms. Additionally, we analyzed the synergistic impact of gums and antimicrobial agents on susceptibility and resistance of selected pathogenic microorganisms.

\section{Materials and Methods}

\section{Culture activation}

Stock culture of Escherichia coli O157:H7 (ATCC 700927), Salmonella enterica (ATCC 4345111), Listeria monocytogenes (ATCC 19116), and Staphylococcus aureus (ATTC 49775) strains were previously purchased from ATCC and store at $-80^{\circ} \mathrm{C}$ in the Microbiology laboratory at the Center for Excellence in Post Harvest Technologies (Kannapolis, NC, USA). Bacterial cultures were activated in tryptic soy broth (TSB, BBL, Sparks, MD, USA) and incubated at $37^{\circ} \mathrm{C}$ for $16 \mathrm{~h}$ in a shaker. Activated culture was streaked plated on tryptic soy agar (TSA, BBL, Sparks, MD, USA) and incubated at $37^{\circ} \mathrm{C}$ for $24 \mathrm{~h}$ to obtain pure colonies which were then used immediately for growth study.

\section{Treatment preparation with different gums}

Five gums including carrageenan-maltodextrin $(\mathrm{CM})$, pectin $(\mathrm{PE})$, locust bean gum (LB), xanthan (XA), and agar (AG) (TIC GUMS Inc., Maryland, GA) were each gradually dissolved into the $200 \mathrm{ml}$ batches of TSB at $0.5 \%(\mathrm{w} / \mathrm{v})$, pasteurized at $110^{\circ} \mathrm{C}$ for $15 \mathrm{~min}$ and cooled to $50^{\circ} \mathrm{C}$ before use. Sterile TSB without gum served as a negative control $[17,18]$.

\section{Determination of bacterial growth}

Growth study was conducted according to the method by KarltonSenaye et al. $[17,18]$ with a slight modification. Bacterial inoculum was prepared by serial dilution in $0.1 \%$ peptone water (BBL, Sparks, MD, USA). Aliquots $(1 \mathrm{ml})$ from appropriate serial dilutions were aseptically added to each $200 \mathrm{ml}$ batch of TSB (BBL, Sparks, MD, USA). Batches of sterilized TSB containing $0.5 \%$ of different gums were inoculated with $0.05 \%$ of inoculum at a final inoculum level of 3 $\log \mathrm{CFUml}^{-1}$ and initial counts were determined. Samples without gum served as the control. Inoculated samples were spiral plated on TSA, and incubated at $37^{\circ} \mathrm{C}$ for $16 \mathrm{~h}$ to determine initial bacterial counts. Inoculated samples were then incubated at $37^{\circ} \mathrm{C}$ for $16 \mathrm{~h}$, serially diluted and aliquots were spiral plated on TSA, incubated at $37^{\circ} \mathrm{C}$ for $24 \mathrm{~h}$. Bacterial enumeration was carried out using a color QCount ${ }^{\circ}$ Colony Counter (Advanced Instruments Inc., MA, USA) to determined the final bacterial population $[17,18]$.

\section{Determination of bacterial population during refrigerated storage $\left(4^{\circ} \mathrm{C}\right)$}

After the final bacterial population were determined, the inoculated samples containing $0.5 \%$ of different gums were refrigerated at $4^{\circ} \mathrm{C}$ to determine bacterial survival under refrigerated condition in the presence of the different gums. Refrigerated samples were spiral plated on TSA bi-weekly for 45 days and then incubated at $37^{\circ} \mathrm{C}$ for $24 \mathrm{~h}$ to determine the final bacterial population using a color QCount ${ }^{\circledR}$ Colony Counter (Advanced Instruments Inc., MA, USA).

\section{Determination of synergism and antimicrobial activity}

Each bacterial strain was treated with $0.5 \%$ gums according to Karlton-Senaye et al. [17] as previously described and tested by agar disk diffusion method on Mueller Hinton II Agar (MHA, BBL, Sparks, MD, USA) according to the methods by Clinical and Laboratory Standards Institute for susceptibility to the following antimicrobial agents [19]: tetracycline (TET) $30 \mu \mathrm{g}$; doripenem (DOR) $10 \mu \mathrm{g}$; imipenem (IMP) $10 \mu \mathrm{g}$; cefixime (CFM) $5 \mu \mathrm{g}$; cipropoxacin (CIP) $5 \mu \mathrm{g}$; ceftazidime (CAZ) $30 \mu \mathrm{g}$; kanamycin (KAN) $30 \mu \mathrm{g}$; and meropenem (MEM) $10 \mu \mathrm{g}$ (BBL, Sparks, MD, USA. Standard antibiotic disks (BBL, Sparks, MD, USA) containing the following recommended minimum inhibitory concentrations of each antimicrobial agents were placed in duplicates in appropriate intervals on MHA in duplicates: tetracycline (TET) $30 \mu \mathrm{g}$; doripenem (DOR) $10 \mu \mathrm{g}$; imipenem (IMP) $10 \mu \mathrm{g}$; cefixime (CFM) $5 \mu \mathrm{g}$; cipropoxacin (CIP) $5 \mu \mathrm{g}$; ceftazidime (CAZ) 30 $\mu \mathrm{g}$; kanamycin (KAN) $30 \mu \mathrm{g}$; and meropenem (MEM) $10 \mu \mathrm{g}$ (BBL, Sparks, MD, USA). Susceptibility of the foodborne pathogens to the antibiotic agents and sterile water were also tested as negative control and positive control, respectively. Zones of inhibition were measured in millimeters and their average determined. The experiments were performed in duplicates and replicated three times.

\section{Data analysis}

Each experiment was conducted multiple times in a randomized block design. The mean and standard deviation values were calculated from duplicate tested samples from three replicates.

\section{Results}

Results of the growth study of Escherichia coli O157:H7 (ATCC 700927), Salmonella enterica (ATCC 4345111), Listeria monocytogenes (ATCC 19116), and Staphylococcus aureus (ATTC 49775 ) in the presence of $0.5 \%$ gums during $16 \mathrm{~h}$ incubation at $37^{\circ} \mathrm{C}$ are shown in Figure 1. Compared to the control $(8.36 \pm 0.11 \mathrm{log}$ $\mathrm{CFUml}^{-1}$ ), treatment with the different gums resulted in a slight decrease in the growth of Salmonella enterica with locust bean affecting the least growth of Salmonella enterica $(8.22 \pm 0.06 \log$ $\mathrm{CFUml}^{-1}$ ). Similar to Salmonella enterica, the population of Escherichia coli O157:H7, Listeria monocytogenes and Staphylococcus aureus decreased slightly with treatment with xanthan, locust bean, and pectin carrageenan-maltodextrin, showing little effect of gums on bacterial population (Figure 1). However, the addition of carrageenanmaltodextrin $\left(8.55 \pm 0.16 \log \mathrm{CFUml}^{-1}\right)$ and locust bean $(8.54 \pm 0.17$ $\log \mathrm{CFUml}^{-1}$ ) caused a slight increase in the population of Listeria monocytogenes. No differences were observed in the population of Listeria monocytogenes in the presence of agar and pectin at $8.49 \pm$ $0.10 \log \mathrm{CFUml}^{-1}$.

During refrigerated storage, bacterial population decreased in the presence of all gums with pectin yielding the most pronounced reduction at $2.68 \pm 0.10 \log \mathrm{CFUml}^{-1}$ (Table 1). However, bacterial population remained relatively stable in the control throughout the storage period (Table 1). 
Citation: Karlton-Senaye B, Ayad A, Davis S, Khatiwada J, Williams L (2016) Interaction of Gums and Antimicrobial Agents on Susceptibility of

Page 3 of 7

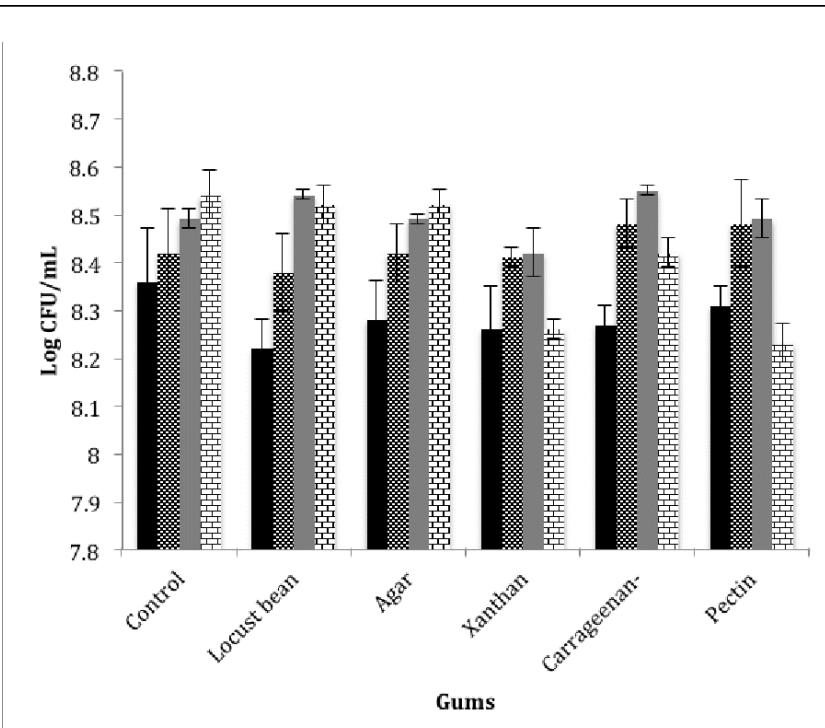

Figure 1: The growth of foodborne pathogens in tryptic soy broth containing different gums $(0.5 \%)$ incubated at $37^{\circ} \mathrm{C}$ for $16 \mathrm{~h}$. Mean $\pm \mathrm{SD}$ of three independent measurements. Keys: Salmonella enterica (Bar 1), Escherichia coli O157:H7 (Bar 2), Listeria monocytogenes (Bar 3) and, Staphylococcus aureus (Bar 4) (Bars from left to right represent the strains of foodborne pathogens tested)

\begin{tabular}{|l|l|}
\hline Gums & Bacterial population $(\log$ CFUml-1) \\
\hline Day 1 & $8.39 \pm 0.10$ \\
\hline Control & $8.25 \pm 0.04$ \\
\hline Locust bean & $8.31 \pm 0.04$ \\
\hline Agar & $8.30 \pm 0.05$ \\
\hline Xanthan & $8.33 \pm 0.06$ \\
\hline Carrageenan-maltodextrin & $8.32 \pm 0.03$ \\
\hline Pectin & $8.39 \pm 0.05$ \\
\hline Day 15 & \\
\hline Control &
\end{tabular}

\begin{tabular}{|l|l|}
\hline Locust bean & $8.51 \pm 0.03$ \\
\hline Agar & $8.45 \pm 0.09$ \\
\hline Xanthan & $8.34 \pm 0.05$ \\
\hline Carrageenan-maltodextrin & $8.53 \pm 0.06$ \\
\hline Pectin & $7.75 \pm 0.06$ \\
\hline Day 30 & $8.38 \pm 0.02$ \\
\hline Control & $8.44 \pm 0.04$ \\
\hline Locust bean & $8.32 \pm 0.04$ \\
\hline Agar & $8.39 \pm 0.08$ \\
\hline Xanthan & $8.51 \pm 0.07$ \\
\hline Carrageenan-maltodextrin & $7.50 \pm 0.03$ \\
\hline Pectin & \multicolumn{2}{|l|}{} \\
\hline Day 45 & $8.38 \pm 0.08$ \\
\hline Control & $8.26 \pm 0.06$ \\
\hline Locust bean & $8.09 \pm 0.07$ \\
\hline Agar & $8.27 \pm 0.06$ \\
\hline Xanthan & $8.30 \pm 0.02$ \\
\hline Carrageenan-maltodextrin & $5.64 \pm 0.03$ \\
\hline Pectin & \\
\hline Mean \pm SD of three independent antimicrobial testing \\
\hline
\end{tabular}

Table 1: Effect of gums on survival of Salmonella enterica during refrigerated storage at $4^{\circ} \mathrm{C}$ for $45 \mathrm{~d}$.

Effect of gums on antimicrobial susceptibility of Salmonella enterica is presented in Table 2. The results showed that the effects of antimicrobial agents were enhanced against the pathogens that were treated with gums compared to the control that were not treated with gums. Treatment with carrageenan-maltodextrin improved the susceptibility of Salmonella enterica against the eight antimicrobial agents tested (Table 2).

\begin{tabular}{|l|l|l|l|l|}
\hline Gums/Antimicrobial agents & Zone of inhibition $(\mathbf{m m})$ & \multicolumn{3}{l|}{} \\
\hline & TET & DOR & IMP & CFM \\
\hline Control & $23.33 \pm 0.58$ & $30.33 \pm 0.58$ & $25.33 \pm 1.15$ & $14.67 \pm 0.58$ \\
\hline Locust bean & $25.33 \pm 1.53$ & $31.00 \pm 1.00$ & $28.67 \pm 1.53$ & $31.33 \pm 2.31$ \\
\hline Agar & $32.33 \pm 2.52$ & $42.33 \pm 1.73$ & $42.33 \pm 0.58$ & $30.67 \pm 0.58$ \\
\hline Xanthan & $25.00 \pm 1.73$ & $30.33 \pm 2.08$ & $28.33 \pm 1.53$ & $29.00 \pm 1.73$ \\
\hline Carrageenan-maltodextrin & $36.00 \pm 1.00$ & $44.33 \pm 2.15$ & $52.00 \pm 2.00$ & $28.00 \pm 1.73$ \\
\hline Pectin & $37.33 \pm 2.31$ & $50.33 \pm 3.51$ & $51.00 \pm 1.00$ & $28.00 \pm 0.58$ \\
\hline
\end{tabular}


Citation: Karlton-Senaye B, Ayad A, Davis S, Khatiwada J, Williams L (2016) Interaction of Gums and Antimicrobial Agents on Susceptibility of Selected Foodborne Pathogens. J Antimicro 2: 121. doi:10.4172/2472-1212.1000121

Page 4 of 7

\begin{tabular}{|c|c|c|c|c|}
\hline $\mathrm{H}_{2} \mathrm{O}$ (negative control) & 0.00 & 0.00 & 0.00 & 0.00 \\
\hline & CIP & CAZ & KAN & MEM \\
\hline Control & $32.67 \pm 1.53$ & $24.33 \pm 1.15$ & $23.67 \pm 1.15$ & $31.00 \pm 1.73$ \\
\hline Locust bean & $33.33 \pm 3.21$ & $28.33 \pm 1.53$ & $24.67 \pm 1.15$ & $35.00 \pm 3.00$ \\
\hline Agar & $39.67 \pm 1.53$ & $29.33 \pm 0.58$ & $27.00 \pm 3.61$ & $40.33 \pm 0.58$ \\
\hline Xanthan & $35.67 \pm 1.15$ & $28.33 \pm 1.15$ & $27.00 \pm 3.46$ & $32.33 \pm 2.08$ \\
\hline Carrageenan-maltodextrin & $34.00 \pm 2.00$ & $31.67 \pm 1.15$ & $29.33 \pm 3.21$ & $40.67 \pm 3.06$ \\
\hline Pectin & $36.00 \pm 1.00$ & $28.67 \pm 1.15$ & $26.67 \pm 2.31$ & $44.33 \pm 2.08$ \\
\hline $\mathrm{H} 2 \mathrm{O}$ (negative control) & 0.00 & 0.00 & 0.00 & 0.00 \\
\hline
\end{tabular}

Table 2: Effect of gums on antimicrobial agents on susceptibility of Salmonella enterica (ATCC 4345111) incubated at $37^{\circ} \mathrm{C}$ for $16 \mathrm{~h}$.

Treatment wtih carrageenan-maltodextrin and pectin in combination imipenem $(52.00 \pm 2.00 \mathrm{~mm})$ against Salmonella enterica resulted in a two-fold increase in zone of inhibition compared to the control $(25.33 \pm 1.15 \mathrm{~mm})$ with carrageenan-maltodextrin affecting the largest zone size (Figure 2). Treatment of Salmonella enterica with locust bean and agar gums also led to a two fold increased the efficacy of cefixime at $31.33 \pm 2.31 \mathrm{~mm}$ and $30.67 \pm 0.58 \mathrm{~mm}$, respectively, compared to their control (Table 2). Treatment with pectin-doripenem $(50.33 \pm 3.51 \mathrm{~mm})$ and carrageenan-maltodextrin-doripenem $(44.33 \pm$ $2.15 \mathrm{~mm}$ ) also increased the zone of inhibition by 1.7 and 1.5 fold, respectively, over the control $(30.33 \pm 0.58 \mathrm{~mm})$ (Table 2$)$.

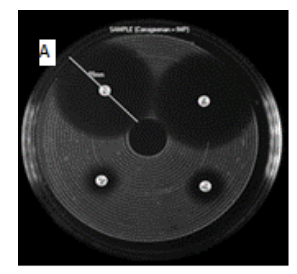

Sample

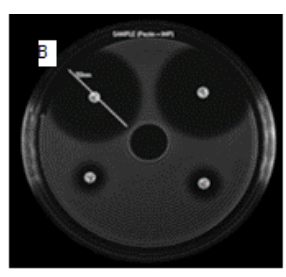

Sample

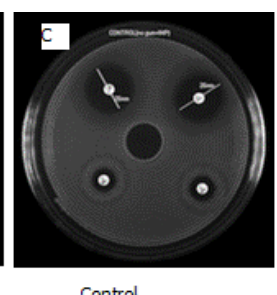

Control
Figure 2: Comparing the synergistic effect of carrageenanimipenem-10 $\mu \mathrm{g}$ (A) and pectin-imipenem-10 $\mu \mathrm{g}$ (B) on susceptibility of Salmonella enterica to the control (C) without gum. exception of kanamycin and meropenem, the susceptibility of Escherichia coli O157:H7 to tetracycline, doripenem, imipenem, cefixime, cipropoxacin, and ceftazime was slightly enhanced with the treatment with gums. Treatment of Escherichia coli O157:H7 with xanthan was found to cause the most increase in the zone of inhibition by doripenem $(33.67 \pm 0.58 \mathrm{~mm})$ and cipropoxacin $(37.67 \pm 0.58 \mathrm{~mm})$ against Escherichia coli $\mathrm{O} 157: \mathrm{H} 7$ compared to their control at $24.67 \pm$ $0.58 \mathrm{~mm}$ and $33.33 \pm 1.15 \mathrm{~mm}$, respectively. There was no difference in susceptibility of Escherichia coli O157:H7 between the treatments and control with the use of kanamycin $(30 \mu \mathrm{g})$ and meropenem $(10 \mu \mathrm{g})$ in control and treatments (Table 3).

Both Staphylococcus aureus (Table 4) and Listeria monocytogenes (Data not shown) were found to be resistance to tetracycline, cefixime, cipropoxacin and kanamycin and susceptible to doripenem, imipenem, and meropenem showing little or no difference between the control and treatments. Susceptibility of both Staphylococcus aureus and Listeria monocytogenes to imipenem, doripenem and kanamycin displayed $1 \mathrm{~mm}$ to $5 \mathrm{~mm}$ increase in the zone of inhibition amongst treated samples compared to their respective control. Again, the zone of inhibition was found to be highest in samples treated with carrageenan-maltodextrin and pectin with the use of imipenem $(24.67 \pm 0.58 \mathrm{~mm})$ and doripenem $(24.67 \pm 0.58 \mathrm{~mm})$ showing most susceptibility effect on Staphylococcus aureus to these antimicrobial agents.

Table 3 shows the effect of gums on susceptibility of Escherichia coli O157:H7 to different antimicrobial agents. Similarly, with the

\begin{tabular}{|c|c|c|c|c|}
\hline \multirow[t]{2}{*}{ Gums/Antimicrobial agents } & \multicolumn{4}{|c|}{ Zone of inhibition (mm) } \\
\hline & TET & DOR & IMP & CFM \\
\hline Control (positive control) & $24.67 \pm 0.58$ & $24.67 \pm 0.58$ & $27.67 \pm 1.15$ & $27.33 \pm 0.58$ \\
\hline Locust bean & $25.67 \pm 0.58$ & $30.33 \pm 1.15$ & $31.00 \pm 1.00$ & $30.33 \pm 1.15$ \\
\hline Agar & $25.67 \pm 0.58$ & $31.67 \pm 1.53$ & $29.67 \pm 0.58$ & $28.67 \pm 1.15$ \\
\hline Xanthan & $26.00 \pm 1.00$ & $33.67 \pm 0.58$ & $28.67 \pm 0.58$ & $30.33 \pm 0.58$ \\
\hline
\end{tabular}


Citation: Karlton-Senaye B, Ayad A, Davis S, Khatiwada J, Williams L (2016) Interaction of Gums and Antimicrobial Agents on Susceptibility of Selected Foodborne Pathogens. J Antimicro 2: 121. doi:10.4172/2472-1212.1000121

Page 5 of 7

\begin{tabular}{|c|c|c|c|c|}
\hline Carrageenan-maltodextrin & $26.00 \pm 1.00$ & $31.33 \pm 1.53$ & $30.33 \pm 1.53$ & $29.67 \pm 1.15$ \\
\hline Pectin & $26.00 \pm 1.00$ & $31.67 \pm 0.58$ & $30.33 \pm 0.58$ & $31.00 \pm 1.73$ \\
\hline \multirow[t]{2}{*}{$\mathrm{H}_{2} \mathrm{O}$ (negative control) } & 0.00 & 0.00 & 0.00 & 0.00 \\
\hline & CIP & CAZ & KAN & MEM \\
\hline Control (positive control) & $33.33 \pm 1.15$ & $27.67 \pm 0.58$ & $27.33 \pm 1.15$ & $35.33 \pm 0.58$ \\
\hline Locust bean & $36.33 \pm 1.15$ & $30.33 \pm 0.58$ & $27.33 \pm 1.15$ & $35.33 \pm 0.58$ \\
\hline Agar & $35.33 \pm 0.58$ & $30.33 \pm 0.58$ & $27.33 \pm 1.15$ & $35.33 \pm 0.58$ \\
\hline Xanthan & $37.67 \pm 0.58$ & $31.33 \pm 1.53$ & $27.33 \pm 1.15$ & $35.33 \pm 0.58$ \\
\hline Carrageenan-maltodextrin & $36.33 \pm 1.15$ & $31.33 \pm 1.53$ & $27.33 \pm 1.15$ & $35.33 \pm 0.58$ \\
\hline Pectin & $37.00 \pm 1.00$ & $31.67 \pm 1.15$ & $27.33 \pm 1.15$ & $35.33 \pm 0.58$ \\
\hline $\mathrm{H} 2 \mathrm{O}$ (negative control) & 0.00 & 0.00 & 0.00 & 0.00 \\
\hline
\end{tabular}

Table 3: Effect of gums and antibacterial agents on susceptibility of Escherichia coli O157:H7 (ATCC 700927) incubated at $37^{\circ} \mathrm{C}$ for $16 \mathrm{~h}$.

\begin{tabular}{|c|c|c|c|c|c|c|c|c|}
\hline \multirow[t]{2}{*}{ Gums/Antimicrobial agents } & \multicolumn{8}{|c|}{ Zone of inhibition (mm) } \\
\hline & TET & DOR & IMP & CFM & CIP & CAZ & KAN & MEM \\
\hline Control (positive control) & $\mathrm{R}$ & $19.67 \pm 0.58$ & $18.33 \pm 0.58$ & $\mathrm{R}$ & $\mathrm{R}$ & $\mathrm{R}$ & $\mathrm{R}$ & $19.33 \pm 0.58$ \\
\hline Locust bean & $\mathrm{R}$ & $21.00 \pm 0.58$ & $22.33 \pm 2.52$ & $\mathrm{R}$ & $\mathrm{R}$ & $\mathrm{R}$ & $\mathrm{R}$ & $21.33 \pm 1.15$ \\
\hline Agar & $\mathrm{R}$ & $23.00 \pm 0.58$ & $22.33 \pm 2.08$ & $\mathrm{R}$ & $\mathrm{R}$ & $\mathrm{R}$ & $\mathrm{R}$ & $22.00 \pm 1.00$ \\
\hline Xanthan & $\mathrm{R}$ & $22.00 \pm 1.00$ & $22.00 \pm 2.00$ & $\mathrm{R}$ & $\mathrm{R}$ & $\mathrm{R}$ & $\mathrm{R}$ & $22.67 \pm 0.58$ \\
\hline Carrageenan-maltodextirn & $\mathrm{R}$ & $21.67 \pm 0.58$ & $24.67 \pm 0.58$ & $\mathrm{R}$ & $\mathrm{R}$ & $\mathrm{R}$ & $\mathrm{R}$ & $21.33 \pm 0.58$ \\
\hline Pectin & $\mathrm{R}$ & $24.67 \pm 0.58$ & $22.33 \pm 1.53$ & $\mathrm{R}$ & $\mathrm{R}$ & $\mathrm{R}$ & $\mathrm{R}$ & $21.33 \pm 0.58$ \\
\hline $\mathrm{H}_{2} \mathrm{O}$ (negative control) & 0.00 & 0.00 & 0.00 & 0.00 & 0.00 & 0.00 & 0.00 & 0.00 \\
\hline
\end{tabular}

Table 4: Effect of gums and antibacterial agents on susceptibility of Staphylococcus aureus (ATCC 49775) during incubated at $37^{\circ} \mathrm{C}$ for $16 \mathrm{~h}$.

\section{Discussion}

In this study we evaluated the effect of gums on the growth of four foodborne pathogenic microorganisms, bacterial death or survival during refrigerated storage and to the combine impact between gums and antimicrobial agents on susceptibility or resistance of selected pathogenic microorganisms.

In our growth study, treatment of pathogenic bacteria with gums caused little or no difference in growth promotion or inhibition. A slight decrease in growth inhibition could be caused by reduced bioavailability of nutrients, which, results from trapping of such nutrients in the culture medium by the polysaccharides [9]. In a study conducted by Yamashita et al. [9] treatment with carrageenan induced the most inhibition against Listeria monocytogenes. In our study, however, treatment with carrageenan-maltodextrin caused a slight increase of Listeria monocytogenes and Escherichia coli O157:H7. A slight increase in the growth of Escherichia coli O157:H7 and Listeria monocytogenes induced by carrageenan-maltodextrin could be due to the ability of these bacteria to use carrageenan-maltodextrin as additional source of nutrient. These observations were expected, as pathogenic bacteria are able to metabolize many food products specifically in polysaccharides.

Decrease in bacterial survival during 45 days at $4^{\circ} \mathrm{C}$ storage period in the presence of all gums with pectin showing the most log reduction at $2.68 \pm 0.03 \log \mathrm{CFU} / \mathrm{ml}$ (Table 1) could be due to excessive acid production and nutrition depletion from the gums, which are long chain polysaccharides and the medium. Increased in the death of the foodborne pathogens during storage indicated that including gums specifically pectin in preservation of food for a period of time could potentially reduce the population of pathogens in the food.

With regards to increased in the susceptibility of foodborne pathogenic bacteria including Escherichia coli O157:H7, Salmonella enterica, Listeria monocytogenes, and Staphylococcus aureus to antibiotics with pectin-IMP being the most effective. It is not surprising that pectin affected the most susceptibility of Salmonella 
enterica. This is because pectin is one of the most digestible and fermentable gums in the gut and could be the most bioavailable gum to the bacteria [19]. The increase in zone of inhibition leading to enhanced susceptibility of Salmonella enterica in the presence of all tested gums with the use of all antimicrobial agents was an indication that tested gums are capable of increasing the efficacy of all the antimicrobial agents tested.

Increased efficacy of antimicrobial agents used in combination of all tested gums for the treatment of shiga toxin-producing Escherichia coli O157:H7 infections, which is the most significant causative vehicle of hemolytic uremic syndrome leading to chronic kidney failure, will definitely be a milestone in antibiotic treatment therapy. In our study, although xanthan, pectin and carrageenan-maltodextrin were found to promote the growth of Escherichia coli O157:H7, it is to interesting to note that these gums also increased the efficacy of tetracycline, doripenem, imipenem, cefixime, cipropoxacin, and ceftazidime, confirming the antimicrobial properties of these gums. A study by Yamashita et al. [9] to determine the bacteriostatic effect of certain polysaccharides against Escherichia coli, Listeria monocytogenes, Salmonella enteridis and Staphylococcus aureus amongst other foodborne pathogens established the antimicrobial effect of pectin against Escherichia coli O157:H7. However, Daoud et al. [10] failed to demonstrate significant antibacterial activity of pectin against Escherichia coli $\mathrm{O} 157: \mathrm{H} 7$.

Our study confirms the susceptibility of Staphylococcus aureus to doripenem and meropenem at discs concentration of $10 \mu \mathrm{g}$ that is in line with Clinical and Laboratory Standards Institute [19]. Although Staphylococcus aureus was also expected to be susceptible to tetracycline, cipropoxacin and kanamycin at the disk concentration used, our study showed otherwise, which is an indication of increasing resistance of Staphylococcus aureus to these antimicrobial agents leading to longer periods of recovery hence the need for alternative antimicrobial agents.

\section{Conclusion}

In conclusion, addition of gums exhibited little or no effect on bacterial growth during 16-hour incubation whereas during refrigerated storage treatment with pectin led to a pronounced decrease in the survival of Salmonella enterica. The treatment of the selected foodborne pathogens with gums showed enhanced efficacy of the antimicrobial agents against Salmonella enterica and Escherichia coli O157:H7 with pectin, carrageenanan-maltodextrin xanthan and agar gums producing most effect. Treatment with pectin and carrageenanan-maltodextrin also led to a slight increased in efficacy of some of the antimicrobial agents against Staphylococcus aureus and Listeria monocytogenes. These findings suggest that carrageenanmaltodextrin, pectin, xanthan, locust bean and agar gums could potentially be used in combination with antimicrobial agents to improve their efficacy in the treatment of foodborne pathogens such Salmonella enterica, Staphylococcus aureus, Listeria monocytogenes and Escherichia coli O157:H7 infections resulting in early recovery. This finding requires future studies to determine molecular basis behind this phenomenon.

\section{Acknowledgement}

This research was supported by State appropriation for the Center for Excellence in Post-Harvest Technologies at the North Carolina Research Campus, Kannapolis, NC.

\section{References}

1. Center for Disease Control CDC (2014) Estimates of Foodborne Illness in the United States.

2. Scallan E, Hoekstra RM, Angulo FJ, Tauxe RV, Widdowson MA, et al. (2011) Foodborne illness acquired in the United States-major pathogens. Emerg Infect Dis 17: 7-15.

3. Yang H, Feirtag JM, Diez-Gonzalez F (2013) Sanitizing effectiveness of commercial "active water" technologies on Escherichia coli O157:H7, Salmonella enterica and Listeria monocytogenes. Food Control 33: 232-238.

4. Marshall BM, Levy SB (2011) Food Animals and antimicrobials: Impacts on human health. Clinical Microbiol Reviews 24: 718-733.

5. Cruz J, Ortiz C, Guzmán F, Fernández-Lafuente R, Torres R (2014) Current Medicinal Chemistry. Antimicrobial peptides: promising compounds against pathogenic microorganisms Curr Med Chem 21: 2299-2321.

6. Gibson GR, Probert HM, Loo JV, Rastall RA, Roberfroid MB (2004) Dietary modulation of the human colonic microbiota: updating the concept of prebiotics. Nutr Res Rev 17: 259-275.

7. Dhanani AS, Gaudana SB, Bagchi T (2011) The ability of Lactobacillus adhesin EF-T to interfere with pathogen adhesion. European Food Research and Technology 232: 777-785.

8. Maganha LC, Rosim ER, Corassin CH, Cruz AG, Faria JA, et al. (2014) Viability of probiotic bacteria in fermented skim milk produced with different levels of milk powder and sugar. International of Journal of Dairy Technology 67: 89-94.

9. Yamashita S, Sugita-konishi Y, Shimizu M (2001) Note in vitro bacteriostatic effects of dietary polysaccharides. Food Sci Technol Res 7: 262-264.

10. Daoud Z, Sura M, Abdel-Massih RM (2013) Pectin shows antibacterial activity against Helicobacter pylori. Advances in Bioscience and Biotechnology 4: 273-277.

11. Karlton-Senaye BD, Ibrahim, SA (2013) Impact of gums on the growth of probiotics. Agro FOOD Industry: Functional food and Nutraceuticals 24: 4.

12. Saha D and Bhattacharya S (2010) Hydrocolloids as thickening and gelling agents in food: a critical review. J Food Sci Technol 47: 587-597.

13. Heydari S, Ehsani MR, Mohammadifar MA, Ezzatpanah H (2011) Biochemial, microbiological and sensory characteristics of probiotic yogurt containing various prebiotic compounds. Italian J of Food Sci 23: 153-163.

14. Hernandez-Hernandez O, Muthaiyan A, Moreno FJ, Montilla A, Sanz ML, et al. (2012) Effect of prebiotic carbohydrates on the growth and tolerance of Lactobacillus. Food Microbiol 30: 355-361.

15. Ghasempour Z, Alizadeh M, Bari MR (2012) Optimization of probiotic yoghurt production containing zedo gum. International Journal of Dairy Technology 65: 118-125.

16. Karlton-Senaye BD, Tahergorabi R, Giddings V, Ibrahim AS (2015) Effect of gums on the viability and $\beta$-galactosidase activity of Lactobacillus spp. in milk drink. International Journal of Food Science and Technology 50: $32-40$.

17. Karlton-Senaye BD, Williams LL, Ibrahim, SA (2015) Comparing the Effect of Gums on the Growth of Lactobacillus Species in Laboratory Medium and Fluid Milk. Journal of Nutritional Health \& Food Engineering 2.

18. Clinical and Laboratory Standards Institute (2014) Performance standards for antimicrobial susceptibility testing. Nineteenth informational supplement M100-S24. Clinical and Laboratory Standards Institute, Wayne, PA.

19. Slavin J (2013) Fiber and Prebiotics: Mechanisms and health benefits. Nutrients 5: 1417-1435. 